\title{
Determinantes da Localização da Agroindústria Canavieira nos Municípios de Minas Gerais
}

\author{
Paulo Henrique de Lima Siqueira ${ }^{1}$ e \\ Luiz Gonzaga de Castro Júnior ${ }^{2}$
}

Resumo: Durante quase toda a sua história, a economia canavieira de Minas Gerais sempre se apresentou como complementar em relação a outras atividades econômicas nucleares, tanto dentro do próprio estado quanto em relação aos demais estados do Centro-Sul do Brasil. A partir dos anos 1990, a importância econômica dessa atividade no estado aumentou, atraindo grandes investimentos e fazendo com que a região ocupasse posição de destaque na produção canavieira nacional. Especificamente nos municípios mineiros, muitos fatores podem ser atrativos para a instalação de usinas e destilarias, trazendo vantagens e desvantagens econômicas, sociais e ambientais. Este estudo foi realizado com o objetivo de verificar a evolução da agroindústria canavieira em Minas Gerais e quais elementos têm estimulado a localização das usinas e destilarias em determinados municípios deste estado. Com uma análise multivariada de regressão logística, verificou-se que a produtividade, o acesso aos recursos hídricos, a concentração fundiária, as áreas arrendadas, a disponibilidade de mão de obra formal e a renda mais elevada dessa mão de obra são os fatores que determinam a presença de usinas e destilarias nos municípios mineiros, podendo gerar benefícios ou malefícios, que devem ser verificados em estudos posteriores.

Palavras-chaves: Agroindústria canavieira, municípios mineiros, determinantes.

Abstract: During almost all the history of Minas Gerais State, its sugarcane production always presented as complementary to other major economy activities, both inside the state and in other Central-Southern regions in Brazil. From the nineties onwards, the sugarcane activity presented a significant economic importance for the state, with the occupation of the savanna of Minas Gerais and attracting investments. This state began to have a prominence occupation in the ethanol and sugar production in Brazil. Specifically in Minas Gerais State cities, many aspects can attract the installation of mills and distilleries, with economic, social and environmental advantages and disadvantages. This paper verifies the evolution of the sugarcane agroindustry in Minas Gerais and the elements which have encouraged the location of mills and distilleries in some counties. With a multivariate logistic regression analysis, it was found that the yield, the access to water resources, the

\footnotetext{
1 Professor da Universidade Federal de São João Del-Rei (UFSJ) E-mail: p33108@hotmail.com

2 Professor da Universidade Federal de Lavras (Ufla) E-mail: lgcastro@ufla.br
} 
land concentration, leased agriculture properties, the availability of formal workforce and the higher income of this workforce are aspects that have determined the presence of mills and distilleries in Minas Gerais cities, which can result in beneficial or harmful effects that should be verified in future studies.

Key-words: Sugarcane agroindustry, Minas Gerais cities, determinants.

Classificação JEL: Q13, R3.

\section{Introdução}

A presença de qualquer atividade econômica numa determinada região pode trazer vantagens ou desvantagens. Dentre as vantagens, podem ser apontadas as novas oportunidades de empregos, aumento da arrecadação de impostos e novas atividades econômicas em função da necessidade de fornecedores e distribuidores dentro de uma determinada cadeia produtiva. Por outro lado, a poluição do ar, sonora ou mesmo visual, a concorrência desleal e o deslocamento de pessoas para outras localidades poderiam ser fatores negativos.

A produção de cana-de-açúcar foi uma atividade importante para a economia brasileira em diferentes períodos históricos. Foi relevante, principalmente, nos primórdios do século XVI, durante a colonização portuguesa e, mais recentemente, a partir da década de 70, com a implementação do Programa Nacional do Álcool, o Proálcool, cujo objetivo era estimular a produção de etanol, tido como combustível nacional.

A partir de 2003, a produção de etanol no Brasil tem sido favorecida, principalmente em função da parcela destinada, por decreto governamental, na mistura com a gasolina e com a introdução dos carros flex fuel, que podem utilizar tanto a gasolina quanto o etanol. De acordo com os dados sobre a produção de veículos automotores da Associação Nacional dos Fabricantes de Veículos Automotores (Anfavea) disponibilizados pela Unica ${ }^{3}$, o País produziu 2.848.071 carros

3 União das Indústrias de Cana-de-Açúcar. flex fuel em 2011 (88,31\% do total de automóveis comerciais leves), com elevação de mais de $5.811 \%$ em relação à produção de 2003.

Em Minas Gerais, a produção de cana-de-açúcar teve início somente a partir do século XVIII, quando a cultura já não era tão importante economicamente para o País, surgindo como um apêndice de uma nova atividade econômica mais importante, que era a extração de ouro e diamantes. Essa pequena expressão econômica da produção de cana-de-açúcar em Minas Gerais se estendeu durante todo o seu período histórico até meados da década de 90, quando a produção passou a ter importância cada vez maior para o estado.

Quanto à produção de açúcar em Minas Gerais, segundo a Unica, a taxa geométrica de crescimento $^{4}$ foi de $9,73 \%$ entre as safras 1990/1991 e 2011/2012. Assim, o estado mineiro assumiu a segunda posição, que era do Paraná, e que, no mesmo período, teve taxa geométrica de crescimento de 6,82\%. Na temporada 2011/2012, Minas Gerais produziu 3.242.059 toneladas de açúcar, crescimento de $684,63 \%$ em relação à safra 1990/1991, sendo o segundo maior produtor no País, atrás somente de São Paulo. A produção de etanol também aumentou nesse mesmo período, $388,45 \%$, atingindo $2.087 .437 \mathrm{~m}^{3}$ na safra 2011/2012. Em virtude desse crescimento, surgem novos questionamentos quanto às implicações

\footnotetext{
4 Calculada pelo antilog do parâmetro $\beta_{1}$ da regressão $\ln \left(Y_{i}\right)$ $=\beta_{0}+\beta_{1} T+u i$, em que $Y_{i}$ é o valor da produção de açúcar de cada estado e $T$, a variável tendência, calculado pelo autor.
} 
econômicas, sociais e mesmo ambientais da presença dessa atividade nos municípios mineiros.

Alguns estudiosos (SHIKIDA e SOUZA, 2009; NEVES e CONEJERO, 2007; JUNQUEIRA et al., 2009; TONETO JUNIOR e LIBONI, 2008) têm levantado aspectos positivos em relação à presença de usinas em determinados municípios brasileiros. Entre eles podem-se citar: geração de emprego, que diminui a migração para as áreas urbanas, melhorando a qualidade de vida de muitas localidades; diminuição gradativa da mão de obra temporária, em função das exigências legais relativas à extinção das queimadas na colheita da cana, mas com a geração de novos empregos em outras atividades que demandam mão de obra mais qualificada; remuneração salarial superior da cultura de cana em relação às várias outras culturas agrícolas, bem como da indústria de açúcar e álcool em relação às outras indústrias alimentícias; geração de renda e de impostos, além do aumento das transferências de recursos estaduais aos municípios e abertura do mercado internacional ao etanol anidro, devido às políticas governamentais de adição do álcool à gasolina e ao fato de o Brasil ser o único País que tem um programa em larga escala de veículos com motores que utilizam como fontes energéticas o etanol.

Dentre os aspectos prejudiciais para os municípios, determinados estudos (SZMRECSÁNYI et al., 2008; GONÇALVES JÚNIOR et al., 2009; SHIKIDA e SOUZA, 2009; ALTIERI, 2009) apontam para a existência de uma rede de saúde e saneamento no limite de sua utilização e insuficientes para atender a população itinerante ocupada no plantio e na colheita de cana; o desarranjo de atividades produtivas locais importantes para o abastecimento alimentar e para o comércio regional, ameaçadas de desestruturação pela introdução da monocultura de cana em larga escala que substitua atividades preexistentes; concentração fundiária intensificada pela monocultura extensiva resultante da corrida para a aquisição de terras e pelo elevado grau de verticalização da indústria canavieira; sazonalidade da demanda de mão de obra ainda presente em muitas lavouras canavieiras; mecanização do cultivo de cana que prejudica o mercado de trabalho, pois o setor é o que mais emprega analfabetos ou semianalfabetos e eles poderiam ter dificuldades de empregabilidade; possibilidade de dependência por parte dos municípios a somente uma atividade econômica, o que pode comprometer sua economia caso o setor canavieiro sofra crises e concentração na produção em grandes produtores agrícolas que favorece a utilização de uma grande quantidade de insumos agroquímicos - herbicidas e fertilizantes nitrogenados - que provocam graves consequências ambientais.

Considerando-se todos esses elementos positivos e negativos em um contexto de crescimento da agroindústria canavieira no estado de Minas Gerais, questiona-se: quais seriam os fatores que têm favorecido a presença de usinas e destilarias em determinados municípios mineiros? Com isso, este estudo foi realizado com o objetivo de verificar a evolução da agroindústria canavieira em Minas Gerais e quais elementos têm estimulado a localização das usinas e destilarias em determinados municípios deste estado.

Na próxima seção é apresentado um levantamento dos principais estudos sobre vantagens e desvantagens da instalação de usinas e destilarias em diferentes regiões do Brasil. Em seguida, apresenta-se a metodologia utilizada no estudo, destacando-se as descrições sobre análise multivariada logística. Na seção subsequente, apresentam-se a evolução histórica e as características da agroindústria canavieira em Minas Gerais, a partir da década de 90 e os principais fatores que têm contribuído para seu desenvolvimento e relevância econômica. A seguir, abordam-se os aspectos que têm estimulado a presença da agroindústria canavieira nos municípios mineiros e, por fim, as considerações finais e as sugestões de pesquisas futuras.

\section{Impactos econômicos da presença de usinas e destilarias nos municípios}

Alguns autores têm apontado vantagens relacionadas à presença da agroindústria canavieira, do ponto de vista econômico, na geração 
de empregos, no aumento da arrecadação de impostos e na dinamização econômica. Segundo Toneto Júnior e Liboni (2008), baseando-se nos dados da Relação Anual e Relações Sociais (Rais), do Ministério do Trabalho e do Emprego e da Pesquisa Nacional por Amostra Domiciliar (PNAD) do IBGE, o setor de cana-de-açúcar foi, em 2006, um dos principais setores, em termos de geração de emprego no Brasil, representando $17 \%$ do emprego na indústria alimentícia e aproximadamente $14 \%$ na agricultura, com cerca de um milhão de empregos gerados. Neste setor encontram-se as melhores condições de remuneração e formalização das relações de trabalho, quando se consideram tanto o emprego no cultivo de cana, cuja remuneração é maior do que a média da agricultura, como nas usinas e no refino de açúcar, em que a remuneração situa-se na média do setor de alimentos. Além disso, o trabalho sazonal tem sido fortemente reduzido e há maior procura por mão de obra mais qualificada.

Shikida e Souza (2009), pesquisando uma usina no município de Cidade Gaúcha, no estado do Paraná, constataram uma diminuição no percentual de empregados dispensados ao término da safra entre 1992 e 2005, que passou de $90,8 \%$ para apenas $21,6 \%$, devido à mecanização no corte, em função das pressões ambientais e à escassez de mão de obra na região para o corte manual da cana. Isso aconteceu porque, apesar da queda do número de pessoas empregadas no setor rural, não houve queda significativa no número total de empregados da empresa, pois o crescimento nos setores industrial, administrativo, agrícola e laboratório entomológico compensou a queda do setor rural. Além disso, o número de empregados na fábrica passou de 186, em 1992, para 275, em 2000, sendo responsável por $37,9 \%$ do emprego do setor indústria de transformação do município, além de 67,8\% do emprego dos setores agropecuário, de extração vegetal e de pesca da cidade.

Em estudo de Junqueira et al. (2009), também no Paraná, verificou-se que a maioria das usinas adota ou buscará adotar a colheita mecanizada em função do aumento das pressões competiti- vas de mercado, da escassez de mão de obra para o corte manual da cana e das pressões ambientais para a extinção da queima da palha da cana. Verificaram, ainda, a escassez de mão de obra mais qualificada, justamente para trabalhar com essas novas máquinas agrícolas, demandando treinamento e qualificação.

Outro aspecto positivo relacionado à presença de usinas e destilarias nos municípios é o aumento da arrecadação de impostos. De acordo com Silva e Pontili, citados por Shikida e Souza (2009), são recolhidos, a cada ano, mais de R\$ 12 bilhões aos cofres públicos. Shikida e Souza (2009) verificaram, ainda, que a usina de Cidade Gaúcha ajudou a elevar as suas receitas correntes, no que se refere às receitas de transferências de recursos estaduais, com sua contribuição para o Valor Adicionado Fiscal. Além disso, as receitas próprias desse município também cresceram, entre 1980 e 2004, levando a um aumento de $64,1 \%$ da sua arrecadação tributária.

Além disso, a Contribuição de Intervenção sobre o Domínio Econômico (Cide), instituída em 19 de dezembro de 2001, também foi relevante para a arrecadação de impostos, incidente sobre a importação e a comercialização de combustíveis, cujo montante arrecadado deve subsidiar os preços e o transporte do álcool combustível, do gás natural e dos derivados de petróleo, e ao financiamento de projetos ambientais relacionados com a indústria do petróleo e do gás e de programas de infraestrutura de transportes (BARROS e MARJOTA-MAISTRO, 2005).

Quanto à dinamização econômica, Shikida e Souza (2009) verificaram que, antes da instalação da usina em Cidade Gaúcha, havia menor crescimento urbano, maior êxodo rural e maior perda de população total em relação à mesorregião paranaense e que, após a sua instalação, ocorreram perda menos acentuada da população rural e crescimento urbano mais acelerado que a média dos municípios integrantes dessa mesorregião. Além disso, a usina doou 150 hectares para construção de 220 casas, em uma vila rural, para fixar as pessoas na cidade, intensificando a circulação econômica e criando renda para o município. 
Outro aspecto que ainda pode dinamizar a economia local é a possibilidade da abertura de novos mercados nacionais e internacionais para o etanol brasileiro, especialmente para o etanol anidro, pois, segundo Neves e Conejero (2007), as políticas governamentais de diferentes partes do mundo vêm estimulando a adição de etanol na gasolina.

Um dos fenômenos observados na agroindústria canavieira brasileira nos últimos anos, e alvo de muita controvérsia, é o nível de concentração, tanto das propriedades agrícolas produtoras de cana-de-açúcar como das unidades esmagadoras. Szmrecsányi et al. (2008), comparando o Censo Agropecuário de 1985 com o de 1995-1996, verificaram que, no Brasil, a lavoura canavieira constitui uma monocultura extensiva, pois as áreas médias dos estabelecimentos especializados na produção de cana-de-açúcar têm sido maiores do que as dos demais dedicados a outras lavouras, com exceção da silvicultura em alguns estados, e da silvicultura e da pecuária em Minas Gerais. Além disso, nesse período, os mesmos autores verificaram que o número de estabelecimentos agrícolas tem diminuído, enquanto as áreas médias aumentaram na maioria dos estados, mostrando uma concentração fundiária. Eles observaram, ainda, que a participação de cana própria nos volumes totais moídos pelas unidades dos principais estados produtores do CentroSul do Brasil permaneceram acima de 50\% no período de 1984 a 2006; que o aumento de mais de $70 \%$ da produção de cana esteve atrelado aos maiores produtores que mais que duplicaram seu fornecimento e que as propriedades canavieiras pertencentes ou controladas pelas indústrias canavieiras ocupam áreas de terras muito maiores dos que as que realmente cultivam, devido à sua integração vertical.

Quanto à concentração das unidades esmagadoras, o que se tem verificado, a partir do ano 2000, é um intenso processo de fusões e aquisições tanto de empresas nacionais quanto estrangeiras. De acordo com a Unica, em 2009, o setor de açúcar e álcool respondeu por cerca de $25 \%$ das transações na indústria de alimentos e agronegócio.
Em Minas Gerais, em um estudo de Hersen et al. (2008), foi demonstrado que, nos anos-safras de 1996/97 até 2005/06, houve aumento na concentração na produção da agroindústria canavieira mineira, com aumento dos índices de concentração $\mathrm{CR}_{4}$ de $50,55 \%$ a $59,49 \%$ e de HirschmannHerfindahl Index (HHI) de 0,0937 para 0,1259, no período ${ }^{5}$.

Se a concentração é positiva ou negativa, existe controvérsia entre pesquisadores e estudiosos. Shepherd (1999) argumenta que todas as firmas procuram aumentar sua parcela de mercado para alcançar lucros maiores e, enquanto essas firmas lutam para superar umas às outras, uma competição efetiva ainda existe, resultando em menores custos, menores preços, rápida inovação e amplos benefícios. Entretanto, a partir do momento em que uma ou poucas firmas dominam o mercado, a competição pode ser ineficiente, pois o poder de mercado causa maiores preços e restrição de oferta de produtos, e impõe custos sociais, como ineficiência, inovações mais lentas, injusta concentração de renda e riqueza, reduzida liberdade de escolha, etc. Shepherd (1999) argumenta, ainda, que esses custos podem ser compensados se houver economia de escala ou performance superior das firmas dominantes.

Por outro lado, os economistas da Escola de Chicago argumentam que eficiência relativa apropriada por uma firma é o que determina sua posição na estrutura de mercado e o seu comportamento. Assim, monopólio ocorre somente quando uma firma for mais eficiente, gerando benefícios ao invés de malefícios. Essa escola argumenta que todos os mercados não têm imperfeições significativas e o mercado de capitais, em particular, é perfeito (SHEPHERD, 1999).

Especificamente na agroindústria canavieira, têm sido encontrados, em alguns estudos, elementos negativos e outros positivos quanto à concentração.

\footnotetext{
5 CR4 é taxa de concentração, calculada pelo somatório da participação das quatro maiores usinas ou grupos sobre o total de cana moída em Minas Gerais, e o HHI é o somatório da participação de todas as usinas ou grupos elevados ao quadrado.
} 
Salgado Júnior et al. (2009), pesquisando 26 usinas paulistas, verificaram que não existia relação direta entre o tamanho das usinas e a eficiência operacional, ou seja, a eficiência operacional não estaria relacionada com a capacidade de moagem da usina, indicando nenhum benefício resultante de maior escala de produção e, consequentemente, da concentração. Quanto às propriedades agrícolas, Szmrecsányi et al. (2008) argumentam que a concentração fundiária, representada pela apropriação das propriedades agrícolas pelas grandes usinas e destilarias, pelo grau de parentesco com os proprietários delas ou pela participação acionária, pode fazer com que haja substituição da produção de outras culturas. Além disso, a expansão canavieira em Minas Gerais, Goiás, Mato Grosso e Mato Grosso do Sul tem provocado verdadeira corrida para a aquisição de terras, por empresários, com o objetivo de implantar novas unidades esmagadoras e por numerosos investidores, que visam arrendá-las ou revendê-las aos primeiros, elevando os preços e a concentração fundiária.

Somado a isso, existe a possibilidade de que, de acordo com Point; Gutierrez (2009), o aumento da produção de biocombustíveis, como o da cana-de-açúcar, afete o suprimento global de alimentos e, no longo prazo, a sustentabilidade da produção agrícola, além de fazer com que os países em desenvolvimento que produzem alimentos tenham de escolher entre produzir alimentos para consumo ou para energia, atendendo a demanda dos países desenvolvidos, o que pode comprometer sua segurança alimentar.

Altieri (2009) chama a atenção para o fato de que o aumento da escala industrial na produção de biocombustíveis para a geração dos chamados combustíveis verdes, provenientes da produção em massa de milho, cana-de-açúcar, soja, óleo de palma e outras culturas, pode ser prejudicial, pois, além de não reduzir o efeito estufa da emissão de gases, desloca dezenas de milhares de fazendeiros, diminui a segurança alimentar em muitos países, acelera o desflorestamento e aprofunda a depredação ecológica do modelo de agricultura industrial, trazendo novos problemas econômicos, ambientais e sociais. A concentração na produção em grandes produtores agrícolas favorece a utilização de uma grande quantidade de insumos agroquímicos, em particular herbicidas e fertilizantes nitrogenados, que provocam graves consequências ambientais. Em regiões com poucos recursos hídricos, a produção de biocombustíveis pode diminuir a disponibilidade futura de água para irrigação e outras opções de desenvolvimento.

Por outro lado, entre os benefícios da concentração, Macedo et al. (2010) observaram, em seu estudo, que as usinas maiores tinham desempenhos socioambientais estatisticamente superiores ao das menores e defenderam políticas públicas que tivessem como foco regular a ação socioambiental das usinas e destilarias a partir dos aspectos de melhorias traçados pela análise de benchmarking entre as empresas eficientes e não eficientes, visando níveis ótimos de ação socioambiental. Quanto às propriedades agrícolas, Toneto Junior e Liboni (2008) constataram que, nas propriedades de cana, predominam as relações de trabalho com carteira de trabalho, resultando em maior grau de formalização do setor, maior participação de contribuintes para a previdência e maior concentração de trabalhadores em idade média.

Dentre os aspectos negativos da presença de usinas e destilarias nos municípios, Szmrecsányi et al. (2008) observaram, junto a prefeitos e dirigentes de associações de produtores agrícolas do oeste de São Paulo, que a rede de saúde e saneamento já estava no limite de sua utilização e sem capacidade para atender à população itinerante ocupada no plantio e na colheita de cana, além do desarranjo de atividades produtivas locais importantes para o abastecimento alimentar e para o comércio regional, ameaçadas de desestruturação pela introdução da monocultura de cana, podendo substituir as atividades preexistentes.

Shikida e Souza (2009) alertam, ainda, para o risco de que o município fique dependente de somente uma atividade econômica, podendo comprometer sua economia, caso essa atividade econômica sofra crises espontâneas. 
Gonçalves Júnior et al. (2009), estudando as atas das 11 reuniões da Câmara Setorial do Açúcar e do Álcool, que é constituída por 47 representantes de 36 entidades, das quais 20 são representantes patronais, 14 governamentais e dois da classe trabalhadora, verificaram que, no período de junho de 2003 a janeiro de 2006, não houve muitas discussões quanto aos aspectos socioambientais, com exceção das preocupações quanto à qualificação dos trabalhadores, pois o setor é o que mais emprega analfabetos ou semianalfabetos. Com a mecanização do setor, esses trabalhadores poderiam ter dificuldades quanto à sua empregabilidade, talvez por ter somente dois representantes da classe trabalhadora e de não haver a presença de nenhum representante que defenda interesses ambientais. O que prevaleceu nas discussões foi a "queda de braço" entre a sanha tributária do estado contra a iniciativa privada.

Point e Gutierrez (2009) e Altieri (2009) chamam a atenção para as ameaças socioambientais da mudança no uso da terra para a produção de culturas de matéria-prima de biocombustíveis em larga escala, pois elas são intensivas no uso de terras e água, reduzindo as áreas para a produção de alimentos e a preservação ambiental, e têm maior impacto sobre os preços dos alimentos do que no preço da energia. Segundo esses autores, poucos estudos científicos têm atentado para isso, já que a indústria dos biocombustíveis tem sido dominada pelas políticas e os interesses de poucas grandes companhias, em um mundo dirigido amplamente pelas políticas neoliberais com regras de mercado que têm forte inclinação contra regulação ou qualquer restrição de mercado para proteger o ambiente, o clima ou as comunidades. Além disso, os biocombustíveis estariam associados diretamente com a produção de transgênicos, negligenciando o impacto das mudanças genéticas, mesmo em plantas não alimentares, na segurança alimentar, pois se podem criar novas espécies de pragas em plantas. Florestas, biodiversidade, saúde do solo, água limpa e emissão de gases estufas continuam sendo "externalidades" na contabilidade, da qual vão sendo sacrificadas pelo real lucro rápido.
Parte expressiva do mundo tem se movido na direção da utilização de biomassa vegetal na produção de combustíveis, não por causa da preocupação pela consciência ambiental, ou sobre a real escassez de combustíveis fósseis ou a evidência irrefutável da mudança climática global, mas porque os biocombustíveis representam oportunidades de negócios num mercado não atendido (SICARD, 2009).

Apesar dessas considerações ambientais, Neves e Conejero (2007) defendem que não se pode comparar o etanol do milho e de outros grãos com o etanol da cana-de-açúcar, pois as outras fontes concorrem diretamente com alimentos, enquanto isso não ocorre para o etanol da cana.

\section{Metodologia}

O primeiro passo para a realização deste estudo foi fazer um levantamento bibliográfico da evolução histórica da economia canavieira no estado de Minas Gerais, processo importante para relacionar os principais motivos que provocaram o atraso e as mudanças ocorridas a partir da década de 90, que alavancaram essa atividade econômica no estado. Junto a essa análise bibliográfica, foi realizada uma comparação da produção de cana-de-açúcar entre as mesorregiões de Minas Gerais e destas com a de outros estados do País.

De acordo com o Sistema de Acompanhamento da Produção Canavieira do Ministério da Agricultura, Pecuária e Abastecimento - Mapa (2011), atualmente, a produção mineira de açúcar e etanol é sustentada por 45 unidades industriais em 42 municípios mineiros. Para analisar a probabilidade da existência de uma usina em determinado município, utilizou-se a regressão logística que, segundo Corrar et al. (2009), busca explicar ou predizer valores de uma variável dependente categórica, em função de valores conhecidos de outras variáveis independentes, que podem ser categóricas ou métricas, possibilitando tanto classificar os fenômenos ou indivíduos em catego- 
rias específicas quanto estimar a probabilidade de ocorrência de determinado evento ou de que um fenômeno venha a se enquadrar nessa ou naquela categoria.

A variável dependente é a presença (1) ou a ausência (0) de usina ou destilaria em determinado município. De acordo com os estudos dos tópicos anteriores, as variáveis independentes são:

- produtividade de cana-de-açúcar (Pt): calculada pela divisão entre a produção total sobre a área colhida, com dados disponibilizados pelo Censo Agropecuário do IBGE em 2006;

- concentração fundiária (C): calculada pela divisão entre a área total em hectare sobre o número de estabelecimentos, com dados disponibilizados pelo Censo Agropecuário do IBGE em 2006;

- arrendamento (Arr): relação percentual das propriedades arrendadas sobre a área total das propriedades, com dados disponibilizados pelo Censo Agropecuário do IBGE em 2006;

- recursos hídricos (Hd): número de estabelecimentos, por município, que têm nascentes, rios, riachos, lagos naturais, açudes, poços ou cisternas, disponibilizados pelo Censo Agropecuário do IBGE em 2006;

- mão de obra formal (Form): taxa de emprego no setor formal de cada município em 2007, com dados disponibilizados pelo Índice Mineiro de Responsabilidade Social, da Fundação João Pinheiro, calculado pela relação entre emprego formal sobre o total de mão de obra;

- rendimento médio do trabalho formal (Rend): de cada município, disponibilizado em 2007, pelo Índice Mineiro de Responsabilidade Social, da Fundação João Pinheiro, cotado em valores reais de dezembro de 2008, por empregado formal;

- imposto líquido (Imp): imposto líquido de cada município, em 2006, em milhares de reais, com dados disponibilizados pelo Índice Mineiro de Responsabilidade Social, da Fundação João Pinheiro, cotado em valores reais de dezembro de 2008;

- adubo químico nitrogenado (Nit): variável utilizada como proxi para verificar a emissão de poluentes e constituída pelo percentual das propriedades que utilizaram adubo químico nitrogenado sobre o total de propriedades, com dados disponibilizados pelo Censo Agropecuário do IBGE em 2006.

Espera-se uma relação positiva entre todas as variáveis independentes com a variável dependente, ou seja, os municípios que apresentarem maior produtividade, concentração fundiária, arrendamento, recursos hídricos, mão de obra formal, rendimento médio do trabalho formal, imposto líquido e adubo químico nitrogenado terão maior probabilidade de hospedarem alguma usina ou destilaria, conforme as discussões teóricas dos tópicos anteriores.

Neste trabalho, foi feita a regressão logística com 851 municípios mineiros, desconsiderando dois, cujos dados sobre a concentração fundiária não estavam disponíveis. Contudo, isso não prejudicou as análises, pois em nenhum deles havia uma esmagadora de cana-de-açúcar.

De acordo com Corrar et al. (2009) e Field (2009), para a validação do modelo de regressão linear, os dados observados devem ter um relacionamento linear e, quando a variável dependente é categórica, essa hipótese é violada. Além disso, isso inviabiliza a probabilidade de o evento aumentar ou diminuir linearmente em relação à função estatística. Para contornar as dificuldades inerentes ao modelo linear, efetua-se uma transformação logística na variável dependente, mantendo a forma de relacionamento linear, enquanto o próprio relacionamento em si não é linear. Esse processo se dá, primeiramente, convertendo a variável dependente numa razão de chances e, em seguida, transformando-a numa variável de base logarítmica, evitando-se a predição de valores menores que zero e maiores que 1 da variável dependente: 
Razão de chance $=\frac{P(\text { evento })}{1-P(\text { evento })}$

$\ln \left(\frac{P(\text { evento })}{1-P(\text { evento })}\right)=b_{0}+b_{1} x_{1 i}+b_{2} x_{2 i}+\ldots+b_{k} x_{k i}$

No lado esquerdo da Equação 2 tem-se o logaritmo natural da razão de chance e, no direito, as variáveis independentes e os coeficientes estimados, que expressam mudanças no log da razão de chance. A razão chance pode ser obtida elevando-se a constante matemática e ao expoente composto dos coeficientes estimados, conforme Equação 3, chegando-se ao objetivo final de identificar a probabilidade associada à ocorrência de determinado evento, conforme Equações 4 e 5.

$$
\begin{aligned}
& \left(\frac{P(\text { evento })}{1-P(\text { evento })}\right)=e^{\left(b+b_{1} x_{1}+b_{2} x_{2}+\ldots+b_{k} x_{x i}\right)} \\
& P(\text { evento })=\frac{e^{\left(b+b_{1} x_{1}+b_{2} x_{2}+\ldots+b_{k} \times x_{k}\right)}}{1+e^{\left(b+b_{1} x_{1}+b_{2} x_{2}+\ldots+b_{k} x_{x}\right)}}
\end{aligned}
$$

ou

$$
P(\text { evento })=\frac{1}{1+e^{-\left(b+b_{1} x_{1}+b_{2} x_{2}+\ldots+b_{k} x_{i k}\right)}}
$$

A transformação logística da qual resulta a Equação 5 geralmente é desenvolvida por meio do método da máxima verossimilhança, que é uma forma de estimar parâmetros de distribuição de probabilidades que maximizem a função verossimilhança:

$$
\begin{aligned}
& \text { verossimilhanç̧̧a }(V L)= \\
& =\sum_{i=1}^{n}\left\{Y_{i} \ln \left(P\left(Y_{i}\right)\right)+\left(1-Y_{i}\right) \ln \left[1-P\left(Y_{i}\right)\right]\right\}
\end{aligned}
$$

em que $Y_{i}$ é o evento e $n$ é o número de observações.

A verossimilhança é baseada na soma das probabilidades associadas com a saída real e a prevista, e tem-se que valores altos da estatística de verossimilhança indicam uma aderência pobre do modelo porque, quanto maior for esse valor, mais observações não explicadas existirão (FIELD, 2009).
Para testar a significância do modelo ajustado, utiliza-se o modelo da razão verossimilhança, testando-se as hipóteses:

$$
\text { Ho: } b_{1}=b_{2}=\ldots=b p=0
$$

ou seja, o modelo não é estatisticamente significativo, ou

$$
\mathrm{H}_{1}: \mathrm{bi} \neq 0(\mathrm{i}=1, \ldots, \mathrm{p})
$$

ou seja, modelo significativo estatisticamente.

Se o modelo não for significativo, não é possível predizer a probabilidade do "sucesso" a partir das variáveis independentes no modelo. A estatística testa a significância da verossimilhança (VL) do modelo só com a constante (Básico), isto é, nenhuma variável independente $(\operatorname{logit}(\mathrm{Y})=$ bo), com a verossimilhança (VL) do modelo com as variáveis independentes (Novo), na combinação linear $\left(\operatorname{logit}(\mathrm{Yi})=\mathrm{bo}+\mathrm{b}_{1} \mathrm{X}_{1 \mathrm{i}}+\mathrm{b}_{2} \mathrm{X}_{2 \mathrm{i}}+\ldots+\right.$ $b_{\mathrm{p}} X_{\mathrm{pi}}$ ) (MAROCO, 2007). O teste baseia-se na fórmula (7):

$$
\begin{aligned}
& x^{2}=2[V L(\text { Novo })-V L(\text { Básico })] \\
& g l=k_{\text {novo }}-k_{\text {básico }}
\end{aligned}
$$

Uma medida de avaliação geral da regressão logística é o Log Likelihood Value, que busca aferir a capacidade de o modelo estimar a probabilidade associada à ocorrência de determinado evento (CORRAR et al., 2009).

A distribuição Qui-quadrado tem graus de liberdade iguais ao número de parâmetros no novo modelo menos o número de parâmetros no modelo básico que, neste último, é sempre igual a 1, a constante, e qualquer modelo subsequente terá um número de graus de liberdade igual ao número de previsores mais 1 (FIELD, 2009).

Para apurar o grau de ajustamento do modelo, utiliza-se o Teste Hosmer e Lemeshow, que nada mais é do que um Teste Qui-quadrado que consiste em dividir o número de observações em cerca de dez classes e, em seguida, comparar as frequências preditas com as observadas, verificando se existem diferenças significativas entre as classificações realizadas pelo modelo e a reali- 
dade observada. Se houver diferenças significativas entre os valores preditos e observados, então, ele não representa a realidade de forma satisfatória. Busca-se, portanto, aceitar a hipótese nula de que não existem diferenças significativas entre os valores preditos e observados (CORRAR et al., 2009).

Para identificar qual ou quais variáveis independentes influenciam significativamente a regressão logística, o Teste de Wald é utilizado, informando se o coeficiente $b$ de cada previsor é significativamente diferente de zero. Apresenta distribuição Qui-quadrada e seu cálculo é dado pelo valor do coeficiente de regressão dividido pelo seu erro padrão (EP) associado, elevado ao quadrado (8).

$$
\begin{aligned}
& \text { Wald }=\left(\frac{b}{E P_{b}}\right)^{2} \\
& E P=\frac{1}{\sqrt{\text { n.P(evento })(1-P(\text { evento }))}}
\end{aligned}
$$

em que n é o número de observações.

Maroco (2007) chama a atenção para o fato de que a estatística de teste só é verdadeiramente válida para amostras de grande dimensão e que os testes dos coeficientes de regressão logística pela estatística de Wald têm ainda maiores probabilidades de erro Tipo I e II do que os testes t na regressão linear, ou seja, se os coeficientes forem muito grandes ou se a dimensão da amostra for pequena, o EP é, geralmente, inflacionado, levando à não rejeição de Ho. Para contornar essa dificuldade, Corrar et al. (2009) recomendam calcular o Likelihood Value com a variável a que se refere o coeficiente sob análise e, depois, renovar esse mesmo procedimento sem essa variável. Comparando-se os dois valores, pode-se verificar se o coeficiente em apreço exerce impactos significativos sobre as probabilidades. Com isso, além da estatística de Wald, tem-se o intervalo de confiança para verificar se, realmente, o coeficiente é significativamente diferente de zero.

Na regressão logística não é possível calcular o $R^{2}$, já que variância da variável dependente depende da probabilidade em que ocorrem os seus valores e, assim, é comum utilizar pseudo- $\mathrm{R}^{2}$, que apenas permite avaliar se o modelo melhora ou não a qualidade das predições, quando comparado a outro que ignore as variáveis independentes. Dentre os pseudo-R²s, têm-se o Cox \& Snell (10) e o Nagelkerke (11).

$$
\begin{aligned}
& \left.R_{C S}^{2}=1-e^{\left[\frac{2}{n}(V L(\text { novo })-V(\text { Básico }))\right.}\right] \\
& R_{N}^{2}=\frac{R_{C S}^{2}}{1-e^{\left[\frac{2(V L \text { Basisico) }}{n}\right]}}
\end{aligned}
$$

O software utilizado para fazer a regressão logística foi o Statistical Package for Social Science (SPSS).

\section{Caracterização da economia canavieira em Minas Gerais}

Os principais fatores que dificultaram o crescimento da economia canavieira em território mineiro, do século XVIII ao XX, tiveram origem no processo histórico de implantação e desenvolvimento da produção de açúcar no estado.

Segundo João Antônio de Paula, apud Affonso de Paula (2005), a formação do território de Minas Gerais, no século XVIII, foi determinada pela atividade econômica itinerante, ou seja, exploração áureo-diamantífera, e pela dispersão de seu povoamento, multiplicando-se as vilas devido às ocorrências minerais e à busca de regiões mais férteis que prevenissem as "grandes fomes" do final do século XVII e início do século XVIII.

Segundo Shikida (1992), no seu processo de implantação e desenvolvimento, do século XVIII até o final do século XIX, a cultura de cana-de-açúcar em Minas Gerais se estabeleceu em regiões próximas de outras atividades econômicas, independente das condições edafoclimáticas favoráveis ao cultivo deste produto agrícola. Destarte, pode-se afirmar que a produção de cana-de-açúcar no estado se estabeleceu, nos seus primórdios, de maneira pouco competitiva.

Diversos fatores explicam os motivos que fizeram com que a agroindústria canavieira de 
Minas Gerais ficasse defasada em relação à de São Paulo, no período da economia cafeeira. Segundo Shikida (1992), em Minas Gerais, os fatores naturais adequados para o cultivo de cana-de-açúcar eram limitados, como o relevo relativamente ondulado e as restrições térmicas e hídricas. A economia cafeeira contribuiu com a agroindústria canavieira por criar uma infraestrutura e uma gama de capital muito maior em São Paulo do que em Minas Gerais, que se tornou uma área marginal em relação às regiões mais dinâmicas dos estados do Rio de Janeiro e São Paulo. Pode-se constatar, ainda, maior preocupação desenvolvimentista da agroindústria canavieira paulista diante da mineira, pois, enquanto o governo paulista se preocupou em criar órgãos de pesquisa com a finalidade de criar variedades mais produtivas de cana-de-açúcar e mais resistentes a doenças, o governo mineiro buscou saídas menos custosas para superar os obstáculos ocasionais.

Em 1930, com o final da I Guerra Mundial, a crise da Bolsa de Nova York e a superprodução recorde de açúcar, entre outros fatores, ocorreu uma queda acentuada do preço do açúcar no mercado externo. O governo brasileiro começou a implementar algumas políticas para regulamentar o mercado de açúcar, visando manter os preços em determinado patamar, para atender ao bem-estar, principalmente, dos produtores nordestinos (SZMRECSÁNYI, 1976).

Em 1933, surgiu o Instituto do Açúcar e do Álcool (IAA), que visava o fomento e o controle da produção de açúcar e do etanol em todo o território nacional. Apesar de o IAA ter sido criado para atender aos interesses nordestinos, o Centro-Sul foi retirando a hegemonia do Nordeste na produção de açúcar (LAGES, 1993).

Minas Gerais, no entanto, não conseguiu desenvolver esta atividade, como ocorreu no estado de São Paulo, pois as políticas do IAA contribuíram para o predomínio econômico e político das usinas, mais presentes no estado paulista, sobre as unidades produtivas mais arcaicas dos engenhos e das engenhocas que caracterizavam as unidades existentes em Minas Gerais. Tanto no aspecto econômico da agroindústria canavieira (concentração industrial, mercado consumidor, de trabalho e de terras, entre outros indicadores), como no institucional (decretos e leis), o mais favorecido foi o estado de São Paulo (SHIKIDA, 1992).

Em 1975, depois da primeira crise do petróleo na década de 70 e da queda de preço do açúcar, o governo brasileiro instituiu o Proálcool, que contribuiu com a diversificação da agroindústria da cana-de-açúcar e o aumento de eficiência. A partir de 1975, a produção de etanol passou a representar parcela bastante significativa no valor total de produção, funcionando como um regulador do mercado de açúcar e vice-versa (VIEIRA, 1999). Com o advento do Proálcool, as usinas mineiras, ainda que pouco expressivas, passaram por um processo de modernização que melhorou seu desempenho.

Além disso, a partir da década de 70, com a implementação da chamada Revolução Verde ${ }^{6}$, teve início o processo de ocupação do Cerrado brasileiro, iniciado a partir das regiões mineiras do Triângulo Mineiro e Alto Paranaíba. Nesse período, intensificou-se a produção de cana-deaçúcar, bastante incentivada no decorrer desta década (GARLIPP e ORTEGA, 1998). Nessas regiões, apoiada na expansão da fronteira agrícola com modernização agropecuária e introdução da agroindustrialização, procurou-se construir uma agricultura moderna com a introdução intensiva de capital (CARNEIRO e FONTES, 2005).

Com a crise do Proálcool, entre 1986 e 1995, a desativação do IAA (1990) e a liberalização dos preços do açúcar (1990), do etanol anidro (1997), da cana-de-açúcar (1998) e do etanol hidratado (1999), avultaram-se as diferenças de produtividade existentes na agroindústria canavieira. Com um novo processo de delineamento das atividades do setor sucroalcooleiro, em que o planejamento e as atividades de produção e comercialização deixaram de ser orientados pelo governo e passaram a fazer parte da admi-

\footnotetext{
6 Refere-se à invenção e à disseminação de novas sementes e práticas agrícolas que permitiram um vasto aumento na produção agrícola no Cerrado brasileiro, durante as décadas de 60 e 70 .
} 
nistração privada, as empresas menos preparadas em termos de capacitação tecnológica encerraram suas atividades ou foram incorporadas pelas mais dinâmicas (SHIKIDA e BACHA, 1999; MARJOTTA-MAISTRO, 2002).

Muitas das empresas produtoras de açúcar e etanol não se acostumaram com a diminuição do protecionismo estatal, ampliando seus problemas de endividamento, resultando na diminuição do número de usinas e destilarias, impulsionados pelas mudanças patrimoniais. A tendência que se visualiza no setor é de novas estratégias individuais, baseadas na diferenciação do produto, principalmente pela qualidade, diversificação produtiva, produtividade, especialização, disponibilidade de entrega e abastecimento, buscando-se maior competitividade (MARJOTTA-MAISTRO e BURNQUIST, 1998; BELIK et al., 1998; SICSÚ e SILVA, 2001).

Neste contexto, o setor canavieiro no estado de Minas Gerais passou por diversas transformações, oscilando com períodos de prosperidade e decadência. Após um período de expansão no número de unidades produtivas na década de
80, com a derrocada do Proálcool, o setor viveu um de seus períodos mais críticos no estado, com cerca de $50 \%$ das unidades produtoras desativadas. Entretanto, no final da década de 90, a indústria canavieira de Minas Gerais novamente começou a viver um período de expansão, com crescimento do parque industrial e modernização administrativa e operacional, resultando na melhoria dos níveis de produtividade, qualidade e aumento da produção acima da média nacional (SINDAÇÚCAR-MG, 200?).

Pelos dados da Tabela 1 observa-se a evolução da quantidade produzida de cana-de-açúcar dos cinco maiores estados produtores brasileiros, junto às taxas geométricas de crescimento. A partir do final da década de 90, Minas Gerais tem aumentado a participação na produção e superado a segunda posição, do Paraná.

O crescimento da produção de cana-de-açúcar em Minas Gerais vem sendo acompanhado por uma concentração maior nas mesorregiões Noroeste de Minas, Central Mineira, Oeste de Minas, Triângulo Mineiro/Alto Paranaíba e Sul/Sudoeste de Minas, conforme mostrado na Tabela 2.

Tabela 1. Evolução da produção de cana-de-açúcar, em toneladas, dos cinco maiores estados produtores brasileiros, nas safras de 1999/2000 a 2011/2012

\begin{tabular}{cccccc}
\hline Safra & São Paulo & Paraná & Minas Gerais & Goiás & Mato Grosso Sul \\
\hline 99/00 & 194.234 .474 & 24.351 .048 & 13.599 .488 & 7.162 .805 & 7.410 .240 \\
$00 / 01$ & 148.256 .436 & 19.320 .856 & 10.634 .653 & 7.207 .640 & 6.520 .923 \\
$01 / 02$ & 176.574 .250 & 23.075 .623 & 12.204 .821 & 8.782 .275 & 7.743 .914 \\
$02 / 03$ & 192.486 .643 & 23.892 .645 & 15.599 .511 & 9.922 .493 & 8.247 .056 \\
$03 / 04$ & 207.810 .964 & 28.485 .775 & 18.915 .977 & 13.041 .232 & 8.892 .972 \\
$04 / 05$ & 230.280 .444 & 28.997 .547 & 21.649 .744 & 14.006 .057 & 9.700 .048 \\
$05 / 06$ & 243.767 .347 & 24.808 .908 & 24.543 .456 & 14.559 .760 & 9.037 .918 \\
$06 / 07$ & 263.870 .142 & 31.994 .581 & 29.034 .195 & 16.140 .043 & 11.635 .096 \\
$07 / 08$ & 296.242 .813 & 40.369 .063 & 35.723 .246 & 21.082 .012 & 14.869 .066 \\
$08 / 09$ & 346.293 .315 & 44.829 .652 & 42.480 .968 & 29.486 .508 & 18.090 .388 \\
$09 / 10$ & 361.260 .727 & 45.578 .529 & 50.573 .227 & 40.075 .735 & 23.111 .237 \\
$10 / 11$ & 359.502 .680 & 43.320 .725 & 54.629 .096 & 46.612 .721 & 33.519 .668 \\
$11 / 12$ & 304.229 .861 & 40.505 .746 & 49.846 .451 & 45.220 .066 & 33.859 .650 \\
TGC $(\%)^{a}$ & $7,16^{*}$ & $7,11^{*}$ & $15,50^{*}$ & $18,46^{*}$ & $14,88^{*}$ \\
\hline
\end{tabular}

a Taxa geométrica de crescimento, obtida pelo antilog do parâmetro $\beta_{1}$ da regressão $\ln \left(Y_{i}\right)=\beta_{0}+\beta_{1} T+u i$ menos 1, em que $Y_{i}$ é o valor da produção de cana de cada estado e T, a variável tendência, calculada pelo autor.

* Significativo a $1 \%$.

Fonte: Unica (2012). 
Tabela 2. Produção de cana-de-açúcar, em toneladas, nas mesorregiões de Minas Gerais, nos anos 1990,2000 e 2010

\begin{tabular}{lcccc}
\hline \multicolumn{1}{c}{ Regiões de Minas Gerais } & $\mathbf{1 9 9 0}$ & $\mathbf{2 0 0 0}$ & $\mathbf{2 0 1 0}$ & Variação \% 1990-2010 \\
\hline Noroeste de Minas & 204.710 & 470.910 & 1.908 .360 & 832,23 \\
Norte de Minas & 1.075 .225 & 890.790 & 1.586 .800 & 47,58 \\
Jequitinhonha & 483.545 & 285.330 & 365.285 & $-24,46$ \\
Vale do Mucuri & 334.085 & 389.288 & 665.260 & 99,13 \\
Triângulo Mineiro/Alto Paranaíba & 7.332 .891 & 10.076 .488 & 42.415 .800 & 478,43 \\
Central Mineira & 1.375 .317 & 1.455 .738 & 3.099 .132 & 125,34 \\
Metropolitana de BH & 435.603 & 439.904 & 623.364 & 43,10 \\
Vale do Rio Doce & 453.791 & 455.721 & 719.793 & 58,62 \\
Oeste de Minas & 205.447 & 357.275 & 1.817 .593 & 784,70 \\
Sul/Sudoeste de Minas & 3.427 .314 & 2.345 .753 & 5.458 .949 & 59,28 \\
Campo das Vertentes & 40.940 & 53.472 & 153.255 & 274,34 \\
Zona da Mata & 2.164 .500 & 1.485 .644 & 1.790 .656 & $-17,27$ \\
\hline
\end{tabular}

Fonte: Instituto Brasileiro de Geografia e Estatística (IBGE), 2012.

As regiões Noroeste de Minas, Oeste de Minas e Triângulo Mineiro/Alto Paranaíba foram as que mais incrementaram a produção de cana-de-açúcar, no período de 1990 a 2010, em 832,23\%, $784,70 \%$ e $478,43 \%$, respectivamente. A região Central Mineira, terceira maior produtora, teve incremento de $125,34 \%$. Por outro lado, as regiões do Jequitinhonha e da Zona da Mata diminuíram sua produção em $24,46 \%$ e $17,27 \%$, respectivamente, no mesmo período.

A atividade canavieira, que durante muitos anos esteve concentrada nas regiões da Zona da Mata e Sul/Sudoeste, passou, a partir do final dos anos 1990, a ser transferida para a região do Triângulo Mineiro, principalmente devido aos investimentos realizados pelos principais grupos empresariais nordestinos, atraídos pelas condições topográficas, pelo clima e pela proximidade com São Paulo (SINDAÇÚCAR-MG, 200?).

Segundo a Secretaria de Desenvolvimento Econômico de Minas Gerais (2006), no município de Tupaciguara, a Bioenergética Aroeira Ltda. planejava investir R\$ 180 milhões numa usina e a Usina Itapagipe, R\$ 31 milhões na ampliação da sua unidade de produção localizada no município de Itapagipe. A Secretaria (2007) também relata que, em julho de 2007, o governo de Minas Gerais anunciou investimentos de R\$ 1,3 bilhão em novas usinas, sendo três no Triângulo Mineiro e a quarta na região Noroeste. Os investimentos previstos foram: no Grupo Santa Elisa, de $\mathrm{R} \$ 410$ milhões, para a implantação da Usina Platina Bioenergia, em Ituiutaba, a terceira planta no Triângulo Mineiro; na Companhia Energética Vale do São Simão, de R\$ 350 milhões, no município de Santa Vitória; na Central Energética Monte Alegre de Minas (Cemam), cuja implantação vai demandar investimentos da ordem de R\$ 450 milhões e na Destilaria Vale do Paracatu Agroenergia, no município de Paracatu, no Noroeste de Minas, com investimentos previstos em R\$ 85,2 milhões. Desde 2005, com mais essas quatro novas usinas, são 40 os projetos de implantação e expansão em Minas Gerais, com investimentos previstos em $\mathrm{R} \$ 8,5$ bilhões.

Em suma, apesar das dificuldades do desenvolvimento da agroindústria canavieira em Minas Gerais durante quase toda a sua história, observa-se que o aumento da produção de açúcar e álcool no estado coincide com o crescimento e o deslocamento da produção de cana-de-açúcar para as regiões Oeste de Minas, Noroeste de Minas, Central Mineira e Triângulo Mineiro/Alto Paranaíba, bem como com os investimentos realizados nessas regiões.

Dentre as características que são favoráveis ao desenvolvimento da cultura de cana-de-açú- 
Figura 1. Região propícia à produção de cana-de-açúcar
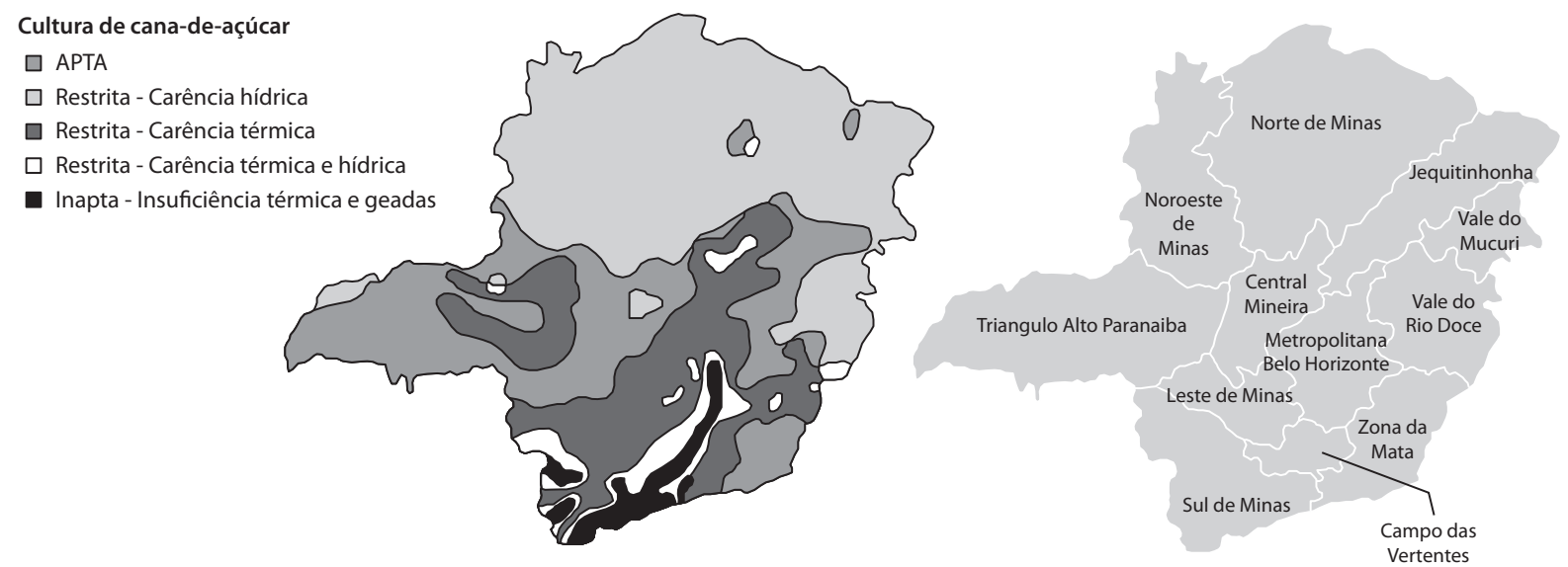

Fonte: Zoneamento agroclimático de Minas Gerais - Geominas ${ }^{7}(1980)$.

Figura 2. Hidrografia do estado de Minas Gerais

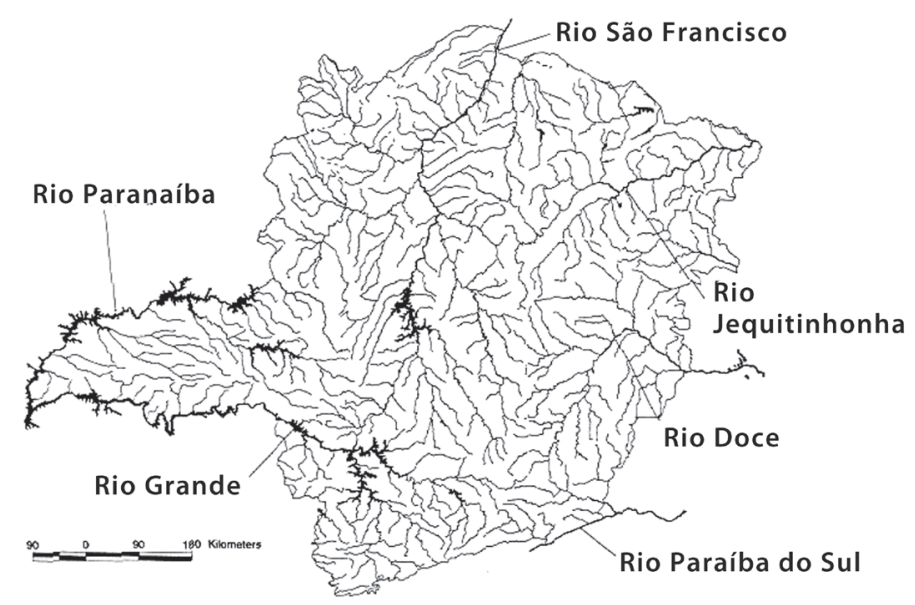

Fonte: Carneiro e Fontes (2005).

car nessas regiões, destacam-se a topografia e o tipo de solo, o que pode ser confirmado pelo zoneamento agroclimático do estado de Minas Gerais, que é favorável à cultura de cana-de-açúcar, conforme mostrado na Figura 1. Observa-se que as regiões do Noroeste de Minas, Oeste de Minas, Central Mineira, Triângulo Mineiro/Alto Paranaíba e Sul/Sudoeste de Minas compreendem uma grande parcela da área mais propícia para a cultura de cana-de-açúcar no estado.

7 Sistema de informações do governo de Minas Gerais, com informações digitais geográficas e georreferenciadas sobre o estado
A classe de solo predominante nessas mesorregiões é o Latossolo, com áreas mais planas na forma de terra "solta", relevo suave e sem impedimentos à mecanização, mas com grandes problemas de fertilidade, com solo geralmente sobre floresta ou, mesmo, cerradão (CARNEIRO e FONTES, 2005).

Além disso, a região possui uma rica bacia hidrográfica (Figura 2), com a do Paraná banhando parte do oeste e do sul do estado, composta pelos rios Paranaíba e Grande. O rio Paranaíba é formado por três bacias secundárias, que são os rios Araguari, Tijuco e São Domingos, limitando, 
com o rio Grande, a região do Triângulo Mineiro. Estas bacias drenam aproximadamente $75 \%$ da área do Triângulo Mineiro. O rio Grande limita a parte do sul de Minas com o estado de São Paulo e merece destaque por abrigar o maior número das principais usinas geradoras construídas pelas concessionárias Cemig e Furnas (CARNEIRO e FONTES, 2005).

A região do Triângulo Mineiro, além das condições edafoclimáticas favoráveis, possui infraestrutura de armazenamento e logística adequada, que facilita o escoamento da produção até o porto de Santos (SHIKIDA et al., 2010).

Na Tabela 3 são observados dados sobre a produtividade agrícola da cana-de-açúcar no Brasil, expressa em tonelada/hectare, nos estados de São Paulo, Paraná e Minas Gerais e nas regiões do Triângulo Mineiro/Alto Paranaíba, Sul/Sudeste de Minas e Central de Minas, nos anos de 1999 a 2010 e a taxa geométrica de crescimento nesse período.

Observa-se que a região do Triângulo Mineiro/ Alto Paranaíba foi, durante todo o período, mais produtiva do que o estado de Minas Gerais, superando também a produtividade nacional e a das outras duas regiões produtoras mineiras. Sua produtividade é equivalente à dos dois maiores e mais produtivos estados produtores de cana-de-açúcar do Brasil, São Paulo e Paraná.

Além disso, de acordo com Carneiro; Fontes (2005), o progresso técnico na agricultura se apresentou de forma bastante desigual, ocorrendo apenas naquelas mesorregiões com características socioeconômicas e ambientais compatíveis com o modelo tecnológico adotado, notadamente as mesorregiões do Sul/Sudoeste de Minas e Triângulo Mineiro/Alto Paranaíba. Com isso, houve maior concentração das propriedades agrícolas e, se por um lado, isso colocou essas mesorregiões entre as mais modernas e tecnificadas do estado e do País, por outro lado, ao empregarem tecnologias maciças na agricultura, relegou o fator trabalho a essa tecnologia, ou seja, perdeu-se a importância da mão de obra (menos qualificada) por meio do estímulo do uso intensivo de capital.

Apesar desses avanços, alguns desafios ainda se fazem presentes para a agroindústria canavieira mineira. Em um estudo de Shikida et al. (2010) sobre as capacidades tecnológicas de 14

Tabela 3. Produtividade da cana-de-açúcar, em tonelada/hectare, dos principais estados produtores e das regiões do Noroeste de Minas, Triângulo Mineiro/Alto Paranaíba e Central de Minas 1999 a 2009

\begin{tabular}{|c|c|c|c|c|c|c|c|}
\hline Ano & Brasil & São Paulo & Paraná & Minas Gerais & Noroeste de Minas & $\begin{array}{c}\text { Triângulo/ } \\
\text { Alto Paranaíba }\end{array}$ & $\begin{array}{l}\text { Central } \\
\text { mineira }\end{array}$ \\
\hline 1999 & 68,15 & 77,16 & 80,10 & 62,63 & 60,48 & 78,68 & 64,16 \\
\hline 2000 & 67,88 & 76,08 & 70,89 & 64,26 & 60,43 & 79,66 & 58,04 \\
\hline 2001 & 69,44 & 77,49 & 81,13 & 64,50 & 65,85 & 75,95 & 63,54 \\
\hline 2002 & 71,44 & 79,94 & 78,25 & 65,60 & 66,45 & 75,21 & 72,26 \\
\hline 2003 & 73,73 & 80,91 & 85,40 & 68,60 & 66,51 & 78,27 & 76,93 \\
\hline 2004 & 73,73 & 81,15 & 81,70 & 72,71 & 72,83 & 83,63 & 75,62 \\
\hline 2005 & 72,85 & 82,60 & 73,46 & 72,72 & 74,99 & 81,79 & 72,54 \\
\hline 2006 & 75,12 & 82,75 & 78,36 & 74,75 & 82,45 & 81,47 & 71,28 \\
\hline 2007 & 77,63 & 84,59 & 85,15 & 77,97 & 84,54 & 84,38 & 69,76 \\
\hline 2008 & 79,27 & 85,21 & 86,18 & 78,78 & 83,83 & 84,73 & 71,70 \\
\hline 2009 & 80,26 & 85,42 & 90,42 & 81,58 & 78,03 & 87,94 & 71,91 \\
\hline 2010 & 79,04 & 85,54 & 77,27 & 81,18 & 77,63 & 86,13 & 73,57 \\
\hline TGC $^{\mathrm{a}}$ & $1,59^{*}$ & $1,13^{*}$ & $0,80^{\mathrm{NS}}$ & $2,67^{*}$ & $3,06^{*}$ & $1,17^{*}$ & $1,35^{* *}$ \\
\hline
\end{tabular}

a Taxa geométrica de crescimento obtida pelo antilog do parâmetro $\beta_{1}$ da regressão $\ln \left(Y_{i}\right)=\beta_{0}+\beta_{1} T+u i$ menos 1 , em que $Y_{i}$ é o valor da produtividade de cana-de-açúcar de cada estado e das regióes mineiras, e T, a variável tendência, calculada pelo autor.

* Significativo a 1\%; ** Significativo a 5\%; NS - não significativo.

Fonte: IBGE, cálculo realizado pelo autor, 2012. 
usinas e destilarias mineiras, foi demonstrado que ainda existem avanços que devem ser implementados por essas esmagadoras no desenho do processo básico, no esboço e na fabricação de equipamentos, na inovação do processo e em Pesquisa e Desenvolvimento (P\&D).

Shikida et al. (2011), fazendo esse mesmo estudo somando 46 unidades paulistas e 11 paranaenses, observaram que o estado de São Paulo foi o que mais apresentou unidades com capacidades tecnológicas no nível avançado dentre os três estados. Na engenharia de processo, por exemplo, enquanto $100 \%$ dos respondentes de São Paulo tinham capacidade tecnológica básica (controle de qualidade, levantamento e análise dos problemas, manutenção preventiva e assimilação de processo tecnológico), $89 \%$, intermediária (redução de custos, modificação de novas tecnologias de processo, adaptação de processo ao novo produto e melhoria na qualidade dos produtos) e $24 \%$, avançada (inovação própria de processo em departamento de P\&D), no estado de Minas Gerais, esses percentuais foram de $86 \%$, $93 \%$ e $0 \%$, respectivamente, mostrando o quanto as usinas e destilarias de Minas Gerais se mostraram aquém das localizadas no estado de São Paulo.

\section{Determinantes da presença das usinas e destilarias nos municípios}

A amostra é composta por 809 municípios que não têm usinas ou destilarias e 42 municípios que têm. Assim, todos os municípios seriam classificados, a priori, como não tendo uma usina, fazendo com que o percentual geral de acertos seja de 95,1\%. Essa classificação atua como referência para avaliar a eficácia do modelo, quando ele passa a operar com as variáveis independentes para predizer a que grupo pertence certo município.

No Quadro 1 são descritas as variáveis no modelo só com a constante, com sua estimativa do coeficiente (B), erro padrão (EP), estatística de Wald, grau de liberdade (g.l.) e a significância ( $p$-valor). $\mathrm{O}$ erro padrão é calculado por $E P=\frac{1}{\sqrt{851.0,049.0,951}}=0,158 \quad \mathrm{e}$ Wald $=\left(\frac{-2,958}{0,158}\right)^{2}=349,384$ e, como o p-valor $=$ 0,000, rejeita-se a hipótese de que a variável constante (bo) seja igual a zero. Finalmente, na última coluna mostra-se a razão de chances $(0,049 / 0,951)$ $=0,052$.

No Quadro 2 mostra-se o teste da razão verossimilhança entre o modelo nulo e os modelos em cada um dos passos, bloco e modelo final, que têm o mesmo valor porque as variáveis independentes foram colocadas ao mesmo tempo. Como o p-valor $=0,000$, pode-se dizer que existe pelo menos uma variável independente no modelo com poder preditivo sobre a variável dependente.

Quanto à qualidade do ajustamento, o valor de - 2 LV (- 2 Log Likelihood) foi de 206,789 e os valores dos pseudos- $\mathrm{R}^{2}$ de Cox \& Snell e de Nagelkerke foram de 0,140 e 0,429, respectivamente, o que mostra que o acréscimo das variáveis

Quadro 1. Variáveis na equação

\begin{tabular}{|c|c|c|c|c|c|c|}
\hline & B & E. P. & Wald & g.l. & p-valor & Exp(B) \\
\hline Constante & $-2,958$ & 0,158 & 349,384 & 1 & 0,000 & 0,052 \\
\hline
\end{tabular}

Fonte: Calculado pelo autor.

Quadro 2. Teste Omnibus dos coeficientes do modelo

\begin{tabular}{|c|c|c|c|}
\hline & Qui-quadrado & g.l. & p-valor \\
\hline Passo & 127,897 & 8 & 0,000 \\
Bloco & 127,897 & 8 & 0,000 \\
Modelo & 127,897 & 8 & 0,000 \\
\hline
\end{tabular}

Fonte: Calculado pelo autor. 
independentes melhora a qualidade do modelo, mas não de maneira muito significativa. Ou seja, considerando o Nagelkerke, o modelo é capaz de explicar $42,9 \%$ das variações registradas na variável dependente. Apesar de pequeno, deve-se considerar a significância do Qui-quadrado.

O teste de Hosmer e Lemeshow resultou em um valor Qui-quadrado igual a 8,165, com p-valor de 0,418 , não significativo, mostrando, portanto, que não existem diferenças significativas entre os valores preditos e observados. Assim, tem-se um indício de que o modelo pode ser utilizado para estimar a probabilidade de uma determinada usina se localizar em determinadas cidades, em função das variáveis independentes.

No Quadro 3 observa-se o percentual de acerto nas classificações, considerando-se as variáveis independentes. Observa-se que houve uma pequena variação em relação ao percentual, considerando a tabela de classificação, a priori, de $95,1 \%$ para $95,8 \%$.

Apesar de se verificar uma redução no nível de acerto em relação à classificação das cidades que não hospedam usinas ou destilarias, já que antes estava $100 \%$ e agora declinou para 99\%, no conjunto, o modelo alcança melhor desempenho, pois, nos municípios que hospedam usinas e destilarias, por serem a minoria, o nível de acerto do modelo era zero e passou para 33,3\%. Considerando-se mais esse indicador, pode-se dizer que, estatisticamente, é conveniente incluir as variáveis independentes no modelo.

Finalmente, no Quadro 4, observa-se que somente as variáveis imposto líquido e adubo químico nitrogenado foram não significativas, não podendo ser aproveitadas na composição do modelo. Entretanto, todas as outras foram significativas, conforme se verifica no Teste de Wald, exercendo, portanto, efeito sobre a probabilidade de uma usina ou destilaria se localizar em determinado município do estado de Minas Gerais. Analisando-se o intervalo de confiança, observa-se que os valores de exp B estão dentro do intervalo inferior e superior, o que mostra que os coeficientes são significativamente diferentes de zero.

Quadro 3. Tabela de classificação com as variáveis independentes

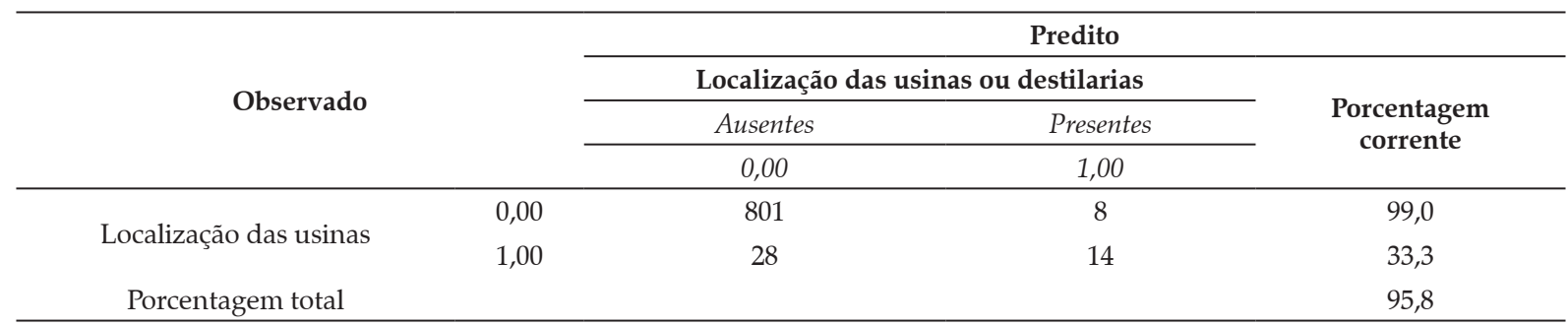

Fonte: Calculado pelo autor.

Quadro 4. Variáveis na equação

\begin{tabular}{|c|c|c|c|c|c|c|c|c|}
\hline & \multirow{2}{*}{ B } & \multirow{2}{*}{ E. P. } & \multirow{2}{*}{ Wald } & \multirow{2}{*}{ g. 1.} & \multirow{2}{*}{ Sig. } & \multirow{2}{*}{$\operatorname{Exp}(B)$} & \multicolumn{2}{|c|}{ 95,0\% C.I. para Exp (B) } \\
\hline & & & & & & & Inferior & Superior \\
\hline $\mathrm{Pt}$ & 0,033 & 0,007 & 24,257 & 1 & 0,000 & 1,033 & 1,020 & 1,047 \\
\hline Conc & 0,009 & 0,002 & 20,265 & 1 & 0,000 & 1,009 & 1,005 & 1,013 \\
\hline Arr & 0,078 & 0,036 & 4,674 & 1 & 0,031 & 1,081 & 1,007 & 1,161 \\
\hline $\mathrm{Hd}$ & 0,001 & 0,000 & 18,815 & 1 & 0,000 & 1,001 & 1,001 & 1,002 \\
\hline Form & 0,036 & 0,016 & 5,007 & 1 & 0,025 & 1,037 & 1,004 & 1,070 \\
\hline Rend & 0,002 & 0,001 & 4,269 & 1 & 0,039 & 1,002 & 1,000 & 1,004 \\
\hline Imp & 0,000 & 0,000 & 0,541 & 1 & 0,462 & 1,000 & 1,000 & 1,000 \\
\hline Adu & $-0,001$ & 0,009 & 0,003 & 1 & 0,957 & 0,999 & 0,981 & 1,018 \\
\hline Const & $-8,813$ & 0,958 & 84,689 & 1 & 0,000 & 0,000 & & \\
\hline
\end{tabular}

Fonte: Calculado pelo autor. 
A partir dos resultados, desenvolveu-se o modelo probabilístico para a presença de usinas ou destilarias nos municípios mineiros:

$$
P(\text { evento })=\frac{1}{1+e^{-(-8,813+0,033 \text { Pt }+0,009 c+0,078 \text { Arr }+0,001 \text { Hd }+0,036 \text { form }+0,002 \text { rend })}}
$$

Para ficar mais claro, de acordo com Gujarati (2000), tomando-se o antilog do j-ésimo coeficiente de inclinação, dele subtrair 1 e multiplicar o resultado por 100, se levantará a variação percentual na chance, devido ao aumento de uma unidade no j-ésimo regressor. Assim, por exemplo, tomando-se o antilog do coeficiente da produtividade (antilog $0,033=1,0336$ ), subtraindo-se 1 e multiplicando-se por 100, tem-se que o aumento de uma unidade na produtividade aumenta a probabilidade de uma usina se instalar numa determinada cidade mineira em 3,36\%.

Esse fato é relevante, considerando que, dos 42 municípios que hospedam alguma usina ou destilaria, $25(59,52 \%)$ estão localizados justamente na região do Triângulo Mineiro/Alto Paranaíba, a mais produtiva do estado mineiro e uma das mais produtivas do País, com produtividade de $87,94 \%$ em 2009, conforme se verifica na Tabela 3.

Verificou-se, ainda, que, quanto maior a parcela da propriedade arrendada sobre total das propriedades, maior a probabilidade da presença de alguma usina ou destilaria no município mineiro em $8,11 \%$ e, quanto maior a concentração fundiária, maior a probabilidade, em 0,9\%. Esses resultados corroboram os de outros autores (SZMRECSÁNYI et al., 2008; ALTIERI, 2009; POINT e GUTIERREZ, 2009), mostrando que os proprietários têm preferido arrendar suas propriedades agrícolas em vez de procurar produzir alguma outra cultura agrícola, aproveitando os preços mais elevados que conseguem com essa atitude. Além disso, a concentração fundiária passa a ser maior, pois a cana-de-açúcar é uma monocultura produzida por extensas propriedades agrícolas.
Com relação à mão de obra, observou-se que o aumento de uma unidade na mão de obra formal aumenta a probabilidade de que uma usina ou destilaria se localize em determinado município em $3,67 \%$, e que o aumento de uma unidade na remuneração dessa mão de obra formal aumenta essa probabilidade em $0,2 \%$. Este resultado também foi observado nos estudos de Toneto Júnior e Liboni (2008), mostrando as melhores condições de remuneração e de formalização das relações de trabalho no emprego no cultivo de cana e nas usinas e destilarias, além de uma remuneração mais elevada nas propriedades produtoras de cana-de-açúcar.

Finalmente, outro aspecto relevante que tem provocado a presença de usinas ou destilarias em determinados municípios mineiros é o acesso aos diferentes recursos hídricos. Municípios com mais propriedades com acesso aos recursos hídricos têm maior probabilidade da presença de usinas em $0,1 \%$. Este resultado concorda com o que é mostrado na Figura 2, que mostra a região do Triângulo Mineiro/Alto Paranaíba comportando grande parte da bacia hidrográfica mineira.

Entretanto, quanto aos impactos fiscais e ambientais, observou-se que eles não foram significativos no modelo. Isso ocorreu provavelmente por dois motivos: pequeno número de municípios mineiros que hospedam alguma usina ou destilaria em relação ao total de municípios existentes, diminuindo o valor das probabilidades e inviabilizado a comprovação dessas variáveis; e a padronização dos tributos e dos arranjos institucionais ambientais, ou seja, não tem como um município, por exemplo, alterar o Imposto Sobre Circulação de Mercadorias e Serviços (ICMS) ou outro imposto incidente nesta agroindústria, procurando, assim, determinar ou influenciar sua localização, assim como as leis ambientais são válidas para todo o estado.

Assim, é importante destacar que os valores observados foram adequados aos esperados e que, portanto, reforçam os principais aspectos 
teóricos que vêm exercendo influência econômica nesses municípios mineiros.

\section{Considerações finais}

Com a ocupação do cerrado mineiro e os investimentos de grandes grupos empresariais, a cultura de cana-de-açúcar passou a apresentar grande importância para a economia de Minas Gerais, surgindo como uma atividade implantada de maneira "racional" economicamente, ou seja, que visa a competitividade para atender da melhor maneira possível a demanda do mercado.

Visando verificar quais os motivos que atraem usinas e destilarias para os municípios mineiros, neste estudo observou-se que a produtividade, a concentração fundiária, o arrendamento, o acesso aos recursos hídricos, o acesso à mão de obra formal e a remuneração mais elevada dessa mão de obra foram elementos que favoreceram a presença dessas esmagadoras nesses municípios, conforme verificado em estudos anteriores. Entretanto, os impactos fiscais e ambientais não puderam ser verificados.

Um aspecto relevante que deve ser considerado e que pode não ter permitido gerar resultados mais consistentes é o pequeno número de municípios mineiros que hospedam alguma usina ou destilaria em relação ao total de municípios existentes. Isso pode ter diminuído o valor das probabilidades e inviabilizado a comprovação das duas últimas variáveis. Além disso, os tributos e os arranjos institucionais ambientais tendem a ser padronizados no estado, inviabilizando mudanças que atraiam usinas e destilarias para os municípios. Por outro lado, os resultados foram relevantes na medida em que, apesar dessa desproporção, ainda resultaram em valores significativos e com relações esperadas, conforme os levantamentos bibliográficos.

Estes resultados mostram que, efetivamente, alguns fenômenos estão associados com a presença de usinas e destilarias em determinados municípios, conforme tem sido levantado em outros estudos. Por outro lado, os impactos positivos e negativos desses fenômenos não foram levantados. Sugere-se que novos estudos sejam realizados para descobrir os reais impactos econômicos, sociais e ambientais da presença dessas esmagadoras nos municípios, direcionando possíveis políticas para reforçar os aspectos positivos e mitigar os aspectos negativos da presença dessa atividade produtiva.

\section{Referências bibliográficas}

AFFONSO DE PAULA, R. Z. Ocupação do espaço, formas de produção e território: uma nota sobre a formação territorial de Minas Gerais. Revista Científica da FAMINAS, v. 1, n.2 (maio/ago.) 2005 - Muriaé FAMINAS - Faculdade de Minas, 2005, p. 255-275.

ALTIERI, M. A. The Ecological Impacts of large-scale agrofuel monoculture production systems in the Americans. Bulletin of Science, Technology \& Society, v. 29, n. 3, jun. 2009, p. 236-244.

BARROS, G. S. A. C. e MARJOTA-MAISTRO, M. C. Ajustes nos mercados de álcool e gasolina entre os anos de 1995 e 2000. Revista de Economia Aplicada, São Paulo, v. 9, n. 2, p. 225-256, 2005.

BELIK, W., RAMOS, P. e VIAN, C. E. F. Mudanças Institucionais e seus Impactos nas Estratégias dos Capitais do Complexo Agroindutrial Canavieiro no Centro-Sul do Brasil. Congresso Brasileiro de Economia e Sociologia Rural, 36, 1998. Poços de Caldas. Anais. Brasília: SOBER, 1998, p. 519-532.

CARNEIRO, P. A. S. e FONTES, M. P. F. Aspectos Geográficos e Agrícolas do Estado de Minas Gerais. In: FONTES, R. e FONTES, M. Crescimento e desigualdade regional em Minas Gerais. Viçosa, MG, 2004, p. 151-222.

CORRAR, L. J., PAULO, E. e DIAS FILHO, J M. Análise Multivariada: para os cursos de administração, ciências contábeis e economia. FIPECAFI - Fundação Instituto de Pesquisa Contábeis, Atuariais e Financeiras. 1. ed., 2. reimpr. São Paulo: Atlas, 2009

FIELD, A. Descobrindo a estatística utilizando o SPSS. 2. ed. São Paulo: Artmed Boodman, 2009, 688 p.

GARLIPP, A. A. P. B. D. e ORTEGA, A. C. A Modernização da Agricultura e a Evolução do Emprego no Cerrado: O caso Triângulo Mineiro e Alto Paranaíba. Congresso Brasileiro de Economia e Sociologia Rural, 36, 1998. Poços de Caldas. Anais. v. 2. Brasília: SOBER, 1998, p. 895-907. 
GONÇALVES JÚNIOR, C. A., ALVES, Y. B. e SHIKIDA, P. F. A., STADUTO, J. A. R. e ROCHA JÚNIOR, W. F. da. Um estudo das deliberações da Câmara Setorial do Açúcar e do Álcool, usando análise de correspondência. Revista de Economia e Sociologia Rural. Piracicaba, v. 47, n. 1, jan/mar 2009. p. 183-210

GUJARATI, D. N. Econometria básica. São Paulo: MAKRON Books, 2000.

HERSEN, A., SHIKIDA, P. F. A. E e DAHMER, V. de $S$. Concentração na agroindústria canavieira mineira pós-desregulamentação setorial. In: CONGRESSO BRASILEIRO DE ECONOMIA, ADMINISTRAÇÃO E SOCIOLOGIA RURAL, 46., Rio Branco (AC), 2008. Anais. Rio Branco: SOBER/UFAC, 2008.

IBGE - Instituto Brasileiro de Geografia e Estatística, 2012. Disponível em: <http://www.sidra.ibge.gov.br/> .

JUNQUEIRA, C. P., STERCHILE, S. P. W. e SHIKIDA, P. F. A. Mudança Institucional e o impacto no padrão tecnológico: o caso da mecanização da colheita de cana-de-açúcar no Paraná. Organizações Rurais \& Agroindustriais, Lavras, v. 11, n. 1, 2009, p. 87-105.

LAGES, A. M. G. A Diferenciação Tecnológica na Indústria Sucro-Alcooleira do Brasil, 1993. Dissertação (Mestrado pela CME/PIMES/UFPE) - Universidade Federal de Pernambuco. Pernambuco: UFPE, 1993. 199p.

MACEDO, M. A. da S., CÍPOLA, F. C. e FERREIRA, A. F. R. Desempenho social no agronegócio brasileiro: aplicando DEA no segmento de usinas de processamento de cana-de-açúcar. Revista de Economia e Sociologia Rural. Piracicaba, v. 48, n. 1, jan/mar 2010. p. 223-243.

MARJOTTA-MAISTRO, M. C. Ajustes nos Mercados de Álcool e Gasolina no Processo de Desregulamentação. Tese (Mestrado - ESALQ/USP) - Escola Superior de Agricultura "Luiz de Queiroz" / Universidade de São Paulo. Piracicaba: ESALQ/USP, 2002, 180p.

MARJOTTA-MAISTRO, M. C. e BURNQUIST, $\mathrm{H}$. L. A Avaliação do fornecimento de Açúcar para as Indústrias Alimentícias do Estado de São Paulo: Uma Pesquisa de Mercado. In: CONGRESSO BRASILEIRO DE ECONOMIA, ADMINISTRAÇÃO E SOCIOLOGIA RURAL, 36, Poços de Caldas (SP), 1998. Anais. Brasília: SOBER, 1998, p. 599-609.

MAROCO, J. Análise estatística - com utilização do SPSS. 3. ed. Lisboa: Edições Silabo Lda, 2007, 822 p.

MINISTÉRIO DA AGRICULTURA, PECUÁRIA E ABASTECIMENTO - MAPA, 2011. Disponível em: $<$ http://www.agricultura.gov.br/>.
NEVES, M. F. e CONEJERO, M. A. Sistema agroindustrial da cana: cenários e agenda estratégica. Economia Aplicada, v. 11, n. 4, out.-dez. 2007, p. 587-604.

POINT, L. e GUTIERREZ, A. P. Overview on biofuels from a European Perspective. Bulletin of Science, Technology \& Society, v. 29, n. 6, 2009, p. 493-504.

SALGADO JUNIOR, A. P., BONACIM, C. A. G. e PACAGNELLA JUNIOR, A. C. Aplicação da Análise Envoltória de Dados (DEA) para avaliação de eficiência de Usinas de açúcar e álcool da região Nordeste do Estado de São Paulo. Organizações Rurais $\mathcal{E}$ Agroindustriais, Lavras, v. 11, n. 3, 2009, p. 494-513.

SECRETARIA DE DESENVOLVIMENTO ECONÔMICO DE MINAS GERAIS. Investimentos em novas usinas de açúcar e álcool somam $\mathrm{R} \$ 1,3$ bilhão. 22 de julho de 2007. Disponível em: <http:// www.desenvolvimento.mg.gov.br/pt/noticias/285investimentos-em-novas-usinas-de-acucar-e-alcoolsomam-r-13-bilhao>.

SECRETARIA DE DESENVOLVIMENTO ECONÔMICO DE MINAS GERAIS. Triângulo recebe mais duas usinas de açúcar e álcool. 21 de dezembro de 2006. Disponível em: < http://www.desenvolvimento. mg.gov.br/pt/noticias/134-triangulo-recebe-mais-duasusinas-de-acucar-e-alcool>.

SHEPHERD, W. G. The Economics of Industrial Organization. Waveland Press, 1999.

SHIKIDA, P. F. A. A Evolução da Agroindústria Canavieira em Minas Gerais de 1705 a 1995. Tese (Mestrado ESALQ/USP) - Escola Superior de Agricultura "Luiz de Queiroz" / Universidade de São Paulo. Piracicaba: ESALQ/USP, 1992, 154p.

SHIKIDA, P. F. A., AZEVEDO, P. F. de. e VIAN, C. E. de F. Desafios da Agroindústria Canavieira no Brasil pós-desregulamentação: uma análise das capacidades tecnológicas. Revista de Economia e Sociologia Rural, Piracicaba, v. 49, n. 3, p. 599-628, jul./set. 2011.

SHIKIDA, P. F. A., AZEVEDO, P. F. de e VIAN, C. E. de F. Uma análise das capacidades tecnológicas da agroindústria canavieira em Minas Gerais. Revista de Economia e Agronegócio, Viçosa (MG), v. 8, n. 2, p. 251277, mai/ago 2010.

SHIKIDA, P. F. A. e BACHA, C. J. Evolução da Agroindústria Canavieira Brasileira de 1975 a 1995. Revista Brasileira de Economia, v. 53, n. 1, p. 69-89, jan/ mar 1999.

SHIKIDA, P. F. A. e SOUZA, E. C. de. Agroindústria canavieira e crescimento econômico local. Revista de 
Economia e Sociologia Rural. Piracicaba, v. 47, n. 3, jul/set 2009, p. 569-600.

SICARD, T. E L. Between Development and Environment: Uncertainties of Agrofuels. Bulletin of Science, Technology E Society, v. 29, n. 3, jun. 2009, p. 226-235.

SICSÚ, A. B. e SILVA, K. S. Desenvolvimento Rural na Zona da Mata Canavieira do Nordeste Brasileiro: Uma Visão Recente. In: Seminário: Dilema e Perspectivas para o Desenvolvimento Regional com Ênfase Agrícola e Rural no Brasil na Primeira Década do Século XXI. Anais. Santiago, Chile [s.n.], 11 a 13 de dez. 2001. Disponível em: <www.fao.org/regional/Lameria/prior/>.

SINDAÇÚCAR-MG. Realidade e Perspectivas do Setor Sucroalcooleiro de Minas Com Foco no Desenvolvimento Social e Econômico. [S.I.: s.n.,] 200?. 20p.

SZMRECSÁNYI, T. Contribuição à Análise do Planejamento da Agroindústria Canavieira do Brasil. Tese (Doutorado - Departamento de Economia e Planejamento
Econômico do Instituto de Filosofia e Ciências Humanas da Universidade Estadual de Campinas). Campinas, UNICAMP, 1976, 508 p.

SZMRECSÁNYI, T., RAMOS, P., RAMOS FILHO, L. O. e VEIGA FILHO, A. de A. Dimensões, riscos e desafios da atual expansão canavieira. Brasília: Embrapa Informações Tecnológicas, 2008. 150 p.

TONETO JUNIOR, R. e LIBONI, L. B. Evolução recente do mercado de trabalho da cana-de-açúcar no Brasil (1995-2006). Organizações Rurais E Agroindustriais, Lavras, v. 10, n. 3, p. 455-474, 2008.

UNICA (União da Indústria de Cana-de-Açúcar), 2012. Disponível em: <http://www.unica.com.br/ dadosCotacao/estatistica/ $>$.

VIEIRA, R. J. Restruturação do PROÁLCOOL e Continuidade da Produção de Álcool Combustível no Brasil. Tese (Mestrado em Economia Rural) - Universidade Federal de Viçosa. Viçosa: UFV, 1999, 134p. 
